\title{
Reglas para la operación de la cláusula de terminación unilateral
}

\section{Rules for the operation of the unilateral termination clause}

DOI: https://doi.org/10.17981/juridcuc.16.1.2020.15

Artículo de reflexión. Fecha de Recepción: 11/01/2020. Fecha de Aceptación: 15/04/2020

\author{
Katherine Marrugo Saldarriaga \\ Colegio Mayor de Nuestra Señora del Rosario. Bogotá (Colombia) \\ ab.katherinemarrugo@outlook.com
}

Para citar este artículo:

Marrugo, K. (2020). Reglas para la operación de la cláusula de terminación unilateral. Jurídicas CUC, 16(1), 339-370. DOI: http://dx.doi.org/10.17981/juridcuc.16.1.2020.15

\section{Resumen}

La dogmática jurídica tradicional colombiana enseña que los principios fundamentales del contrato privado constituyen la autonomía privada de las partes y la fuerza ejecutoria del contrato. No obstante, respecto a las formas de terminación del mismo, a pesar de que algunos sectores de la doctrina no comparten la idea de que las partes tengan posibilidad de pactar una cláusula que permita un acto o declaración de voluntad de una de las partes, de dar por terminado el contrato anticipadamente y de pleno derecho; la cual en el tráfico contractual es una práctica común. Bajo este escenario, el objetivo principal de este escrito consiste en establecer los requisitos para la redacción y para el ejercicio de dichas cláusulas, con el fin de contribuir a minimizar los riesgos de abuso y violatorios del principio de Buena Fe. Para este fin se abordó la revisión de reglas de operación en la doctrina colombiana, para continuar con el estudio de seis cláusulas de terminación unilateral pactadas en la práctica contractual. Del análisis conjunto de la información sustraída de estas fuentes, se identificó que a pesar de la existencia de reglas desarrolladas en la doctrina para la elaboración de las cláusulas, las mismas no necesariamente coinciden con el nivel de creatividad y discrecionalidad de los particulares; razón por la cual, este trabajo contiene reglas generales conciliatorias entre las identificadas en la doctrina y las formuladas por la autonomía de los contratantes.

Palabras clave: Autonomía privada; buena fe; contrato privado; reglas; terminación unilateral

\begin{abstract}
Traditional Colombian legal dogma teaches that the fundamental principles of the private contract are the private autonomy of the parties and the enforceability of the contract. However, with respect to the forms of termination of the contract, despite the fact that some sectors of the doctrine do not share the idea that the parties have the possibility of agreeing on a clause that allows an act or declaration of will by one of the parties to terminate the contract early and in its own right; which in the contractual traffic is a common practice. Under this scenario, the main objective of this paper is to establish the requirements for the drafting and exercise of such clauses, in order to contribute to minimize the risks of abuse and violation of the principle of Good Faith. To this end, the review of operating rules in Colombian doctrine was addressed, in order to continue with the study of six unilateral termination clauses agreed upon in contractual practice. From the joint analysis of the information taken from these sources, it was identified that despite the existence of rules developed in the doctrine for the drafting of the clauses, these do not necessarily coincide with the level of creativity and discretion of individuals; for this reason, this work contains general conciliatory rules between those identified in the doctrine and those formulated by the autonomy of the contracting parties.
\end{abstract}

Keywords: Good faith; private autonomy; private contract; rules; unilateral termination 


\section{INTRODUCCIÓN}

De antaño, el ordenamiento jurídico colombiano en materia civil y comercial ha reconocido como principios fundamentales del contrato, el de la autonomía de la voluntad y la fuerza obligatoria del mismo (Bernal-Fandiño, 2013, p. 42). Es importante recordar que, además de que el contrato surge primariamente por "el acuerdo de voluntades aparente entre dos o más personas para crear, modificar o extinguir vínculos jurídicos" (Mantilla y Ternera, 2005, p. 44), por el principio de fuerza obligatoria del contrato, o del pacta sunt servanda, todo contrato legalmente celebrado es una ley para los contratantes e impone a las partes la obligación de acatar lo que hayan acordado de manera voluntaria, por cuanto es vinculante para ellas, como lo sería si fuera impuesto por la ley (BernalFandiño, 2013, p. 43).

En este sentido, dogmáticamente, un contrato legalmente celebrado debe ser cumplido de acuerdo a lo pactado, y no puede terminar por causa diferente a las establecidas en la ley o por acuerdo entre las partes (Código Civil, 1873, art. 1602).

Respecto a las causas de terminación de los contratos de derecho privado, la ley, en el Código Civil (1873, art. 1546) y en el Código de Comercio (1971, art. 870), regula la figura de la Resolución del Contrato, la cual implica principalmente que se produzca la extinción del mismo y de los vínculos jurídicos que éste conlleva (Mantilla y Ternera, 2005), a causa del incumplimiento de lo pactado por una de las partes. Esta potestad se encuentra inmersa en todos los contratos bilaterales (Mantilla y Ternera, 2005), dando la posibilidad de que, por causa del incumplimiento, la parte afectada tenga la opción de resolver o lo que es lo mismo, terminar el contrato o en su defecto, pedir el cumplimiento del mismo.

En cuanto a las causas de terminación por acuerdo entre las partes, no existe duda que, así como los contratantes a través del ejercicio de la autonomía privada, consintieron en la celebración de un negocio jurídico; de la misma manera, a través de otro negocio 
jurídico pueden disponer la terminación del mismo. No obstante, en algunos sectores de la doctrina si existe duda acerca de si las partes de un contrato de derecho privado, en el momento de la determinación del contenido del mismo, pueden pactar una cláusula que permita por un acto o declaración de voluntad de una de las partes, el terminar el contrato anticipadamente, de pleno derecho o sin necesidad de declaración judicial; esto es, de manera unilateral.

La Corte Suprema de Justicia en numerosas sentencias en Sala de Casación Civil, se ha pronunciado al respecto del alcance del derecho de las partes de confeccionar el contenido del contrato, el cual, según el tribunal supremo, no puede ser desconocido por el juez, quien en todo caso solo deberá verificar la observancia de las formalidades previstas en la ley y, como se verá en el desarrollo de este trabajo, de los principios de la Buena Fe y de la cláusula general de Abuso del Derecho.

Es así como la Corte Suprema, en Sentencia SC11287-2016 (2016) cuyo objeto de discusión lo constituyó en una demanda civil ordinaria, para que se declarara la resolución de un contrato de compraventa respecto de un bien inmueble, por incumplimiento del comprador, señaló:

El contenido del contrato sólo puede ser creado, modificado o extinguido por la voluntad de las partes o por la propia ley de modo expreso, sin que sea procedente realizar en tal punto interpretaciones extensivas. Por ello, al juez no le está permitido desconocer el consentimiento de los contratantes dentro de los contornos de la buena fe, como tampoco las causas expresamente previstas en normas positivas para afectar la validez de los convenios o privarlos de sus efectos (Corte Suprema de Justicia. Sala de Casación Civil y Agraria, 2016, p. 12).

En otro pronunciamiento de la Corte Suprema, en Sentencia SC2007-00067, donde se estudió la solicitud de declaración de resolución de un contrato de compraventa; respecto de la potestad del Código Civil (1873, art. 1602), señaló: 
Por supuesto, en desarrollo de tal prerrogativa o en ejercicio del rol asumido, su titular detenta plena disposición para optar por desligarse de uno u otro derecho; perspectiva semejante le procura la posibilidad de crear, modificar o extinguir situaciones jurídicas específicas; luego, nada obsta para explicitar su decisión en un determinado destino, con la seguridad de que la posición asumida contará, con el respaldo de la normatividad vigente; desde luego, ante cualquiera de dichas hipótesis corresponderá observar las formalidades previstas en la ley, así como respetar las salvedades que la misma prevé (Corte Suprema de Justicia, Sala de Casación Civil, 2012, p. 20).

Podría decirse entonces que es perfectamente viable pactar cláusulas de terminación unilateral en contratos privados y que esta facultad excepcional solo será exigible, siempre que el contrato exista y sea válido y eficaz jurídicamente (Sanabria, 2007). Por cuanto, de la aplicación del Código Civil (1873, art. 1602), es posible afirmar que el contenido que las partes hayan determinado para el contrato, en el momento de su negociación, tratativas o celebración -dentro del cual pueden encontrarse las formas de terminación del mismo- en principio se presume legal, por ser producto de la exteriorización de la voluntad, en ejercicio de la autonomía privada de quienes quisieron el contrato y redactaron sus cláusulas y por cuanto dicho contrato existe y es válido (Molina, 2009).

A pesar de lo anterior, existen discusiones en el escenario doctrinal colombiano, acerca de las implicaciones que el pacto de cláusulas de terminación unilateral en contratos de derecho privado, como una prerrogativa de una o varias de las partes, arroja a la seguridad jurídica en la práctica contractual; principalmente porque la terminación unilateral como causa legal de terminación solo se tiene reservada inicialmente de manera excepcional para determinados tipos de contratos. En este sentido, se podría concluir que en Colombia no existe un régimen legal general de terminación unilateral de contratos, al ser circunscritos solamente para unos tipos específicos. 
Las opiniones doctrinales al respecto son variadas con argumentos opuestos entre sí. A manera de ejemplo, Arroyo (2008) consiente que "se requiere de una reglamentación precisa del ejercicio de esa potestad a fin de evitar caer en automatismo que podría resultar en extremo peligroso para el deudor" (p. 55) y considera que el pacto de cláusulas de terminación unilateral del contrato se encuentra dirigido a validar la posibilidad de que la parte para la cual se pactó esta posibilidad de manera excepcional, eventualmente pueda hacer justicia por su propia mano (Arroyo, 2008)

Por su parte, Molina (2009) señala que la posibilidad de poner fin a un contrato sin necesidad de que un juez intervenga parece de lo más natural si se tiene en cuenta que nuestros códigos de derecho privado prevén facultades de ruptura unilateral o extrajudicial.

Está claro que el debate es interesante; sin embargo, el propósito del presente escrito se construye bajo la posibilidad de ofrecer al lector una postura intermedia, partiendo con la convicción de que la inexistencia de normas que prohíban el pacto de una forma de terminación unilateral para los contratos para los cuales la norma no dijo nada (Botero, 2007). La decisión del legislador de acoger formas de terminación unilaterales para unos específicos tipos contractuales, constituye un importante indicio para considerar que no hay obstáculo para que la misma sea ejercida en todos los contratos, ya sean típicos o atípicos (Molina, 2009).

En este escenario, el punto sensible no radica en la estipulación misma de tales cláusulas, sino que el objetivo principal de este planteamiento y que pretende desarrollarse en el presente escrito, consiste en cuáles podrían ser los requisitos para su redacción y para su ejercicio (Hinestrosa, 2007), precisamente para evitar que se produzcan reglas contractuales potencialmente violatorias de los principios que orientan el ordenamiento jurídico colombiano y de manera específica, el derecho de contratos.

Esta pregunta llevará a ubicar antecedentes en la doctrina que se hayan ocupado de proponer requisitos para el ejercicio de esta facultad, que permita realizar un análisis comparativo con algunas de las cláusulas que se han redactado en la práctica contractual colombiana. 


\section{Desarrollo}

\section{Metodología}

El presente artículo pretende hacer una aproximación a los requisitos para el ejercicio de la facultad potestativa de terminación unilateral convencional o cuyo origen se encuentra en una cláusula libremente pactada por las partes de un contrato; y a los límites para su ejercicio dirigidos a alejar a la parte con la prerrogativa, de incurrir en prácticas abusivas. Busca realizar un acercamiento a tendencias doctrinales y regulatorias existentes en Colombia, que han sido reconocidas de manera mayoritaria en la práctica contractual, como argumentos de autoridad para pactar cláusulas creadoras de esta potestad.

Para estos propósitos, en primer lugar, se empleó el método de investigación dogmático jurídico, con base en el cual se realizó una revisión de la doctrina y jurisprudencia colombianas, en conjunto con el método jurídico empírico, mediante el cual se adelantó la revisión de cláusulas de terminación unilateral pactadas en la práctica contractual.

Por último, se realizó un sondeo preliminar de los laudos arbitrales emitidos en el lapso de tiempo entre los años 2010 a 2019, en las bases de datos de la Biblioteca Digital del Centro de Información Empresarial de la Cámara de Comercio de Bogotá, utilizando como recurso de búsqueda la combinación de las palabras: "terminación unilateral".

De los resultados que arrojó la consulta, se tomaron seis laudos de tribunales de arbitramento, constituidos para revisar la validez de la facultad de terminación unilateral, que habían sido pactadas en contratos de derecho privado. La selección de los laudos que se estudian en este trabajo, se limitaron a aquellos en los cuales se controvirtieron cláusulas de terminación unilateral pactadas en contratos para los cuales la ley no prevé la terminación unilateral como forma de extinción del contrato; y cuyos tribunales hayan resuelto a favor de la viabilidad del pacto de dichas cláusulas. 


\section{Aproximación al concepto de terminación unilateral convencional}

Antes de abordar el análisis de los requisitos de operación que podrían pactarse en una cláusula de terminación unilateral, resulta pertinente realizar una aproximación al concepto que se le ha dado a esta, en la normativa y doctrina colombianas.

Es necesario comenzar por precisar que la figura de terminación unilateral no es ajena al ordenamiento colombiano, dentro del cual existe un amplio número de estipulaciones especiales en cuanto a la posibilidad de que un contrato pueda terminarse por un acto jurídico unilateral de una de las partes, sin necesidad de requerir la intervención de un juez que lo declare.

Además de las cláusulas excepcionales reglamentadas para la contratación estatal, "las cuales se constituyen como una de las potestades a través de las cuales, la Administración Pública deja entrever su dominium, es decir, su posición de superioridad frente a sus co-contratantes" (Betancur, Londoño y Múnera, 2017), el derecho colombiano ha permitido la operación de la figura de terminación unilateral de manera específica para ciertos tipos de contratos en materia civil y comercial.

Este trabajo no realizará un compendio y un análisis de estos tipos contractuales y las normas que los regulan (Botero, 2007; Molina, 2009; Rengifo, 2014b; Corte Suprema de Justicia, 2011). No obstante, con la finalidad de bridar al lector un contexto apropiado para el desarrollo del objetivo principal del presente trabajo, se enunciarán someramente algunos de estos tipos contractuales, a manera de ejemplo.

En materia civil, se encuentran el Contrato de Arrendamiento de Servicios Inmateriales, regulado en el Código Civil (1873, art. 2066), donde cualquiera de las partes puede poner fin al servicio cuando quiera. De la misma manera se encuentra el Contrato de Mandato, que permite al mandante revocar el mandato a su arbitrio (Código Civil, 1873, art. 2191). Así como el Contrato de Comodato, en el cual el comodante puede exigir la restitución de la cosa antes del tiempo estipulado, cuando le sobrevenga una necesidad imperiosa y urgente de la misma (Código Civil, 1873, art. 2205). 
En materia mercantil, el Contrato de Mandato así como el Contrato de Agencia Comercial, para referirse a la terminación del contrato utilizan el vocablo "revocar", y en este sentido se estipuló para estos, que el mandante podrá revocar el mandato total o parcialmente, a menos que se haya pactado su irrevocabilidad (Código de Comercio, 1971, art. 1279). De igual manera se encuentran otros tipos de contratos como el Contrato de Fiducia, para el cual se estableció como causal de extinción del mismo, la "revocación del fiduciante, cuando expresamente se haya reservado ese derecho" (Código de Comercio, 1971, art. 1240); y así mismo se reguló para el Contrato de Suministro, donde cualquiera de las partes podrá dar por terminado el contrato (Código de Comercio, 1971, art. 977).

De la misma forma, se encuentran normas especiales para cierto tipo de contratos como el arrendamiento de vivienda urbana (Ley 820, 2003, art. 23), la cual establece requisitos para la terminación unilateral del contrato tanto por el arrendador, como por el arrendatario (Ley 820 (2003, art. 24). Por su parte, la Ley 142 (1994, art. 133.21) regula el contrato de servicios públicos domiciliarios, y contiene la posibilidad del suscriptor o usuario de terminar el contrato de manera unilateral con un preaviso de dos meses.

Habiéndose establecido claridad respecto de existencia normativa en materia de terminación unilateral, es posible comenzar enunciando que el concepto de terminación unilateral convencional se distingue en primera medida porque su uso y aplicación solo podría tener lugar para los tipos contractuales sin respaldo de una norma específica en materia de terminación unilateral, así como para los contratos atípicos; y porque, como consecuencia de lo anterior, este mecanismo de terminación tendrá un origen no legal sino convencional, a través del pacto de una cláusula dentro del contrato.

El estudio pues, de la terminación unilateral convencional tiene importancia en la medida en que, si bien no cuenta con reglas generales de aplicación en la ley colombiana, su uso es común entre particulares y comerciantes, pues generalmente quien ha sido víctima de un incumplimiento no siempre se toma la molestia de iniciar un proceso judicial, sino que prefiere darlo por terminado unilateralmente 
(Molina, 2009), con la principal finalidad de extinguir el vínculo contractual y de las obligaciones que de él resultan y como consecuencia, liberarse del mismo (Molina, 2006).

Dentro de este contexto, las cláusulas de terminación unilateral que se pacten ad nutum, esto es, sin necesidad de alegar ninguna justificación (Molina, 2006), o con ocasión del incumplimiento de una de las partes, guardan relación con las nociones que trae el proceso de modernización del derecho de contratos, cuya finalidad se concreta en organizar de modo más eficiente las relaciones del tráfico en un mercado global (Morales, 2016), en el que los contratantes busquen soluciones prontas y eficaces de los conflictos entre estos, que simplifiquen los trámites y agilicen el empleo de los recursos invertidos (Hinestrosa, 2007).

La Corte Suprema de Justicia (2011) estudió una demanda de declaración de responsabilidad civil extracontractual, por incumplimiento de contratos de afiliación o vinculación de vehículos, fundada en el incumplimiento de los contratos por parte del demandado, por haber terminado el contrato unilateralmente, en contra de la buena fe y la prórroga automática pactada al finalizar su duración mínima; en su tarea de explicar el alcance de la terminación unilateral convencional, expresó:

Estricto sensu, una o ambas partes son titulares de un derecho potestativo para terminar unilateralmente el contrato, sin aquiescencia, aceptación, beneplácito o consentimiento de la otra, cuyo ejercicio desemboca en acto dispositivo recepticio en cuanto debe ponerse en conocimiento de la otra parte, usualmente con un preaviso mínimo, legal o convencional o, en su defecto, congruo, razonable o suficiente, de forma libre salvo disposición contraria (p. ej. Código de Comercio, 1971, art. 1071), exige el escrito para la revocación del seguro), y constitutivo por extinguir el vínculo con efectos liberatorios hacia el futuro (ex nunc) sin alcanzar las prestaciones ejecutadas, cumplidas, consumadas e imposibles de retrotraer, esto es, carece de eficacia retroactiva (ex tunc), cumple la función de terminar el pacto, y por tanto, desligar in futurum a las partes del compromiso sin declaración judicial, menester a propósito de las controversias al respecto (Corte Suprema de Justicia. Sala de Casación Civil, 2011, p. 28). 
A partir de lo anterior, se puede identificar la característica más importante de la terminación unilateral convencional, la cual se resume en la conjunción de dos palabras: Derecho potestativo, señalado por Molina (2006) como "el resultado de la voluntad de uno de los contratantes y no del común acuerdo de las partes" (p. 134). Adicionalmente, este derecho potestativo puede ser ejercido ipso iure, dado que la finalidad del pacto de la cláusula de terminación unilateral en el contrato, radica en que el mismo termine por la sola expresión de la voluntad del contratante con la prerrogativa, sin requerir de intervención judicial declarativa (Hinestrosa, 2007).

Así pues, el no requerir intervención del juez, es otra característica relevante de la terminación unilateral convencional. No obstante, como se ha comprendido en la doctrina, una vez terminado el contrato unilateralmente, el deudor podrá acudir al juez para cuestionar la decisión del acreedor; precisamente porque su ejercicio comporte el riesgo de que su autor lo haga de forma ilegal o abusiva (Molina, 2009).

Otra característica que se encuentra en la doctrina, consiste en que la terminación del contrato de manera unilateral, se puede ejercer solo en contratos de tracto sucesivo. Al respecto, (Molina, 2006), señala que "tal regla se induce de las normas que regulan la terminación de la mayoría de los contratos de ejecución sucesiva" (p. 137), como el contrato de prestación de servicios inmateriales y el contrato de suministros. Además, este autor sostiene claramente que la "terminación unilateral solo tiene relevancia en contratos cuya ejecución se esté desarrollando" (Molina, 2006, p. 130).

Teniendo en cuenta las características de la terminación unilateral convencional descritas, a través de un método deductivo se propone que la cláusula de terminación unilateral se podría entender como el acuerdo mediante el cual, los contratantes de manera expresa, incluyen la prerrogativa o facultad excepcional y potestativa de una o de todas las partes, de terminar de manera unilateral un contrato de ejecución sucesiva, por el advenimiento de una condición específica, como el incumplimiento; o sin mediar justificación alguna y sin declaración judicial, por cuanto su legitimidad es dada por el libre ejercicio de la autonomía privada de las partes. 


\section{Los riesgos de la terminación unilateral convencional y}

los requisitos para el ejercicio de este mecanismo

El principal riesgo de que el pacto de la facultad excepcional de terminación unilateral del contrato puede significar para la seguridad jurídica contractual, radica principalmente en que, en ausencia de régimen legal general aplicable, las reglas para su operación corresponden a las diseñadas por las partes, las cuales pueden ser eventualmente constitutivas de abuso y violatorias del principio de Buena $F e$, lo que puede conllevar que la cláusula sea calificada como abusiva y por ende violatoria de normas imperativas (Oviedo-Albán, 2019).

Por otra parte, de acuerdo a la opinión de Neme (2018) la potestad de dar por finalizado un contrato de manera unilateral constituye la máxima expresión del ius variandi o de la posibilidad de variar el contenido del contrato, dado que dicha facultad genera un derecho subjetivo en cabeza de quien la detenta, entendiéndose como derecho subjetivo, "la facultad atribuida a un sujeto determinado de transformar un estado jurídico mediante su exclusiva manifestación de la voluntad" (Ibañez, 2003, p. 59). Neme (2018) señala que en algunos casos la misma puede resultar inadmisible, en cuanto contraria al derecho, dada la multiplicidad de conductas a través de las cuales dicho derecho puede ser concretado, y así pues, el comportamiento del titular de dicha facultad puede resultar abusivo.

Neme (2008) señala:

La tipicidad del comportamiento abusivo consiste en el hecho de presentarse (...) conforme a una facultad convenida legítimamente por las partes y contraria a la finalidad del negocio, a los intereses de la contraparte, a los fines sociales o de mercado y, en fin, a los principios del sistema que reglan las relaciones contractuales (p. 29).

No queda duda entonces que, por un lado, la inserción de una cláusula de terminación unilateral en un negocio jurídico, debe como primera medida ser el resultado de una discusión y negociación previa de los contratantes, a través de la bilateralidad del consentimiento, el cual se surte $a b$ initio con la aceptación de los términos 
del contrato (Neme, 2018). Razón por la cual esta prerrogativa no podrá ser admisible en los contratos de adhesión.

Y, por otra parte, la buena fe deberá operar como principio rector de todo el iter contractual, pues si bien las particulares estipulaciones de las partes nutren una adecuada interpretación del contrato, de conformidad con la buena fe, tales estipulaciones no podrán prevalecer cuando resulten contrarias al citado principio (Neme, 2014).

Una vez analizados los riesgos que el pacto de una cláusula de terminación unilateral contiene para el tráfico contractual, surge la necesidad de someter su uso o ejercicio a unos criterios de valoración o de control, que permitan determinar las condiciones en las que la misma pueda operar de forma legítima (Neme, 2018).

En la revisión dogmática que se adelantó para este trabajo, se identificó un grupo de autores, quienes hicieron un esfuerzo importante para proponer reglas o condiciones para la operación de la cláusula de terminación unilateral; las cuales, también han sido revisadas de manera parcial por la Corte Suprema de Justicia y algunas de estas son de común aplicación para la terminación unilateral ad nutum y para la terminación unilateral por incumplimiento.

A partir de lo anterior, los requisitos de operación de la terminación unilateral convencional se revisarán en tres grupos así: i) Los relacionados con el incumplimiento que da origen al ejercicio a la potestad, cuando el mismo ha sido pactado como causa para la operación de esta; ii) los que hacen parte de las condiciones para su ejercicio y; iii) los que hacen referencia a la titularidad de la prerrogativa.

Con respecto a la calidad del incumplimiento cuyo acaecimiento provoca la posibilidad de que opere la terminación unilateral, la doctrina ha coincidido en su mayoría en establecer que un requisito deberá consistir en que el incumplimiento como causa debe ostentar un carácter de grave o esencial. Rengifo (2014a) explica que el incumplimiento grave se presenta cuando recae "sobre prestaciones principales y no accesorias, o mejor, que termine afectando sustancialmente la economía de la relación contractual o significativamente el interés del acreedor” (p. 117). 
La Corte Suprema de Justicia (2011), por su parte y sin profundizar, enuncia claramente que el ejercicio de la facultad de terminación unilateral convencional presupone un incumplimiento "de tal gravedad, magnitud, relevancia, significación o importancia, por cuanto no cualquier inobservancia de los deberes de conducta justifica la resolución" (p. 37).

Molina (2009) respecto de esta condición, se apega un poco más al concepto de incumplimiento en un sentido amplio, el cual, de acuerdo con Morales (2016) se caracteriza porque "abarca cualquier manifestación de la falta de realización de las exigencias del contrato" ( $p$. 91). Molina (2009) sugiere la posibilidad de que las partes "eleven a la categoría de esencial, prestaciones que no lo son conforme a los usos y practicas usuales, o que ellas deseen una ejecución minuciosa del contrato" (p. 96). Y, por lo tanto, para esta finalidad deberán "enunciar de manera clara y exacta cuáles serán las obligaciones cuyo incumplimiento dará derecho a poner fin al contrato" (Molina, 2009, p. 96).

La Corte Suprema de Justicia (2011) en consonancia con esto considera necesaria "la indicación particular, clara y precisa de la obligación u obligaciones cuya inobservancia relevante, total o parcial (SGN, sentencia de 29 de abril de 1935), faculta a una o ambas partes, la terminación unilateral del contrato" (p. 37).

Se puede observar que esta condición operaría como un control específico a la autonomía privada de los contratantes, a través de la cual se quiere evitar que, la parte con la prerrogativa actúe de manera excesiva al momento de declarar la terminación unilateral por incumplimiento. Se trata de un requisito establecido para mantener las condiciones de igualdad de la relación contractual, en salvaguarda del deber de lealtad de las partes, con el cual se quieren evitar actuaciones intempestivas y abusivas (Bernal-Fandiño, 2007, p. 21). Cabe recordar que el deber de lealtad se deriva del solidarismo contractual, el cual, según Bernal-Fandiño (2007) "pone en duda la idea de que las partes sean las únicas que deban establecer la oportunidad del contrato, y que el hecho de que sea negociado implique necesariamente que sea equilibrado" (p. 17). 
Un segundo requisito para que la cláusula de terminación unilateral opere cuando se pacte como causa de esta el incumplimiento del contrato, consiste en que la parte que ejerza la potestad debe comunicar al deudor acerca del incumplimiento de este último y de los perjuicios que le está causando, para constituirlo en mora (Sanabria, 2007). De esta manera, la voluntad exteriorizada del acreedor es la que logrará que el mismo termine efectivamente (Molina, 2006), y en casos de incumplimiento, se hace a través de la constitución en mora del deudor.

No obstante, en observancia de los deberes de corrección y lealtad derivados del principio de buena fe, reconocidos también, como cargas de la autonomía privada (Hinestrosa, 2014), al informar el acreedor al deudor acerca de su incumplimiento, debería ir acompañado de un plazo para que el deudor, de acuerdo como lo expresa Rengifo (2014a) "tenga la oportunidad de ajustar su conducta al comportamiento requerido" (p. 123). o para que al vencimiento de aquel, sin más, el contrato quede terminado (Hinestrosa, 2007).

Así, de acuerdo a lo expuesto, la terminación unilateral del contrato por incumplimiento, no operaría automáticamente, por cuanto se esperaría que el deudor rectifique su conducta, según corresponde a la probidad o corrección exigible y el principio de conservación y utilidad del contrato (Corte Suprema de Justicia, 2011, p. 37).

Este plazo no debe ser confundido con el preaviso, el cual, parece cumplir la misma función. Según Molina (2006), el preaviso es el concepto que usa la doctrina para definir "el lapso de tiempo que transcurre entre el momento en que se notifica a la otra parte la intención de desligarse del vínculo jurídico y el momento de la ruptura propiamente dicha” (p. 148). De acuerdo a Molina (2006), la finalidad del preaviso no es lograr el cumplimiento del contrato, sino "proteger a la parte que padece la terminación unilateral de los perjuicios que le pudiere ocasionar una ruptura brutal o intempestiva de la relación contractual" (p. 148). Por lo tanto, este es el recurso que se utiliza como requisito para que opere la terminación unilateral ad nutum, o cuando el acreedor quiere lograr una terminación automática del contrato en caso de incumplimiento, posibilidad que no debe descartarse. 
Sobre el preaviso, Hinestrosa (2007) señala que es "el intervalo entre la comunicación y la cesación de los efectos del contrato" y "debe corresponder a lo que la lealtad y la corrección imponen, aplicadas a la situación concreta" (p. 453). Molina (2006) por su parte menciona:

En cada caso deberá tomarse en consideración el tipo de contrato y las circunstancias particulares en que el mismo se ha formado y ejecutado" y que "son parámetros comúnmente aceptados los siguientes: la antigüedad de la relación contractual, la situación de dependencia económica en que pueda encontrarse un contratante con respecto al otro, la magnitud de los intereses financieros en juego, etc (p. 149).

Por último, sobre los requisitos para la operación de la cláusula de terminación unilateral relacionados con la titularidad de la potestad, en opinión de Hinestrosa (2007), el equilibrio de la concepción y redacción de las cláusulas resolutorias por incumplimiento, se proyecta en la reciprocidad de la prerrogativa. Esto quiere decir, que el pacto de terminación unilateral incluido en el contrato, debería pactarse para todas las partes que intervienen en el negocio jurídico.

En el mismo sentido concluye Molina (2006), tomando como base el régimen legal establecido sobre terminación unilateral en tipos de contratos de ejecución sucesiva. Al respecto señala que, salvo pacto en contrario, esa facultad debe estar a disposición de ambos contratantes, en contratos atípicos a término indefinido (p. 137). La Corte Suprema de Justicia (2011), con un argumento parecido, basado en la necesidad de preservar la paridad o equilibrio objetivo de las partes, la buena fe, la lealtad y evitar abusos, establece que la eficacia de la cláusula de terminación unilateral se subordina a la reciprocidad de la facultad para ambas partes; no obstante, también menciona como viable que la misma sea estipulada para una de ellas.

Adicionalmente sobre la titularidad de la facultad potestativa de terminación unilateral convencional, la doctrina y la Corte Suprema (2011) coinciden al poner de manifiesto que la parte que 
pretende ejercerla, deberá encontrarse cumpliendo con las obligaciones derivadas del contrato o por lo menos, allanarse de cumplirlas (Sanabria, 2007), por cuanto "en los contratos bilaterales ninguno de los contratantes está en mora dejando de cumplir lo pactado, mientras el otro no cumpla por su parte" (Molina, 2009, p. 95).

Hasta aquí podría decirse que, en Colombia, la terminación unilateral convencional, en tanto se trate de la potestad ad nutum o por incumplimiento, ha sido desarrollada de manera importante en la doctrina y la jurisprudencia, las cuales han propuesto reglas para su ejercicio. De acuerdo a los autores consultados, el argumento principal para establecer reglas consiste en dirigirse a las disposiciones jurídicas existentes para los tipos contractuales para los cuales la ley autorizó el uso de la terminación unilateral.

También se observó que dichas reglas reconocen los deberes exigibles de buena fe contractual y abuso del derecho, como controles del contenido contractual. Sin embargo, llama la atención preguntarse acerca de la manera como en la práctica contractual, los particulares han establecido las condiciones para el uso de esta facultad y con base en qué disposiciones o principios han sustentado la redacción de dichas cláusulas, por cuanto, al final, conviene revisar cuál ha sido el alcance que los contratantes le han atribuido a la autonomía privada, para estos propósitos.

\section{Reglas de operación de la terminación unilateral convencional en la práctica contractual}

Las reglas de operación de la terminación unilateral convencional que fueron descritas, no han sido ignoradas por los particulares, quienes toman reglas de los instrumentos conocidos, al momento de redactar dichas cláusulas. Se observa cómo encuentran en la tipicidad contractual, la pauta para que las estipulaciones de estos, eventualmente lleguen a alcanzar el reconocimiento del juez al calificar la aceptabilidad de dichas condiciones (Hinestrosa, 2013).

Hinestrosa (2013) explica que es elemental e inherente a la autonomía privada, que todo individuo sea producto de su ambiente y de la cultura en la que está inmerso, de modo que, al momento 
de disponer de sus intereses, su margen de creatividad es de suyo reducido. No obstante, el uso de la discrecionalidad privada para la determinación de las disposiciones, en este caso, de la cláusula de terminación unilateral, es relevante para que la misma produzca los efectos deseados por las partes del contrato, y es aquí donde campea el reconocimiento por parte de la sociedad y, tras de ella, del Estado, de la autonomía privada, que se afirma y opera por su propio peso social y del poder soberano del ordenamiento para orientarla y encauzarla, pero sin llegar a sustituirla o a desconocerla (Hinestrosa, 2013).

Así pues, el régimen de terminación unilateral convencional, es susceptible de que se desarrolle a partir de las reglas que las partes dispongan, con base en el margen de creatividad e innovación de las mismas (Hinestrosa, 2013).

En concordancia con lo que se ha expuesto en este escrito, acerca de que la causa principal para que los particulares incluyan cláusulas de terminación unilateral en sus negocios jurídicos, consiste en resolver de manera eficiente la disposición de sus intereses, se consideró importante incluir en el presente trabajo, el estudio de laudos arbitrales, por cuanto los mismos son el resultado de la iniciativa constitucional de hacer a la justicia más dinámica y eficiente, con seguridad jurídica a todos sus usuarios y salir de la paquidermia que ha caracterizado al funcionamiento de la justicia en Colombia (Maldonado y Montaña, 2017).

El análisis de dichos laudos se realizó con base en las reglas de operación de la terminación unilateral establecidas en la doctrina y que ya fueron revisadas en este documento, con el fin de realizar una comparación entre estas y las pactadas por las partes en las cláusulas de terminación unilateral estudiadas por los tribunales de arbitramento.

Resultó interesante encontrar cláusulas de terminación unilateral pactadas a favor de solo una de las partes, ignorando aparentemente la regla sobre la reciprocidad de la prerrogativa promovida por los doctrinantes estudiados. A partir de lo anterior, la conclusión inicial se orienta en que una cláusula pactada de esta manera 
sería abusiva, pues, en línea de principio podría tratarse de una predisposición de la parte que ejerza un cierto poder contractual, impuesta a la otra parte quien se encuentra en una condición de debilidad (Gual, 2016).

En el laudo del Tribunal Arbitral de Proveza Ltda para solucionar las diferencias surgidas con BAVARIA SA (Cámara de Comercio de Bogotá. Centro de Arbitraje y Conciliación-CAC, 2011), Proveza presentó como fundamento de su demanda, entre otros, el que la terminación unilateral del contrato por parte de BAVARIA estuvo basada en una cláusula abusiva. Esta cláusula fue pactada en favor de BAVARIA, quien a su vez redactó la propuesta del negocio jurídico de distribución celebrado. Al respecto el Tribunal encontró que, el que fuera el propio destinatario de la oferta del negocio jurídico, este es, BAVARIA, quien redactara la propuesta y los términos y condiciones en que, con su aceptación, habría de quedar formado el contrato entre ellas, por sí sola, no tornaba inválida ni ineficaz la misma, pues si bien BAVARIA ostentaba una posición preeminente respecto de Proveza, no quedó demostrado que se hubiera aprovechado de ella.

El Tribunal estableció su argumento en lo siguiente:

La sola circunstancia de ostentar una posición de dominante frente a la otra parte contratante, no tiene la virtualidad de hacer ineficaces o nulas las condiciones pactadas, salvo que se demuestre que en ejercicio de tal condición superior se hayan impuesto a la otra parte cláusulas abusivas o lesivas de la justicia contractual (inc. 4, art. 333 C.P.).

El Tribunal anota que la sola circunstancia de que BAVARIA hubiera redactado los términos de la oferta, solo implica que esos y no otros serían los términos que aquélla estaría dispuesta a aceptar. Ello se explica, además, en su interés de que las obligaciones de sus contratistas queden expresadas de manera tal que vayan en línea con las que BAVARIA, a su turno, tiene como productor (Cámara de Comercio de Bogotá, CAC, 2011, p. 22).

Otro argumento que simpatiza con la idea de que la cláusula de terminación unilateral pueda ser pactada a favor de solo una de las partes, consiste en que si se reconoce, como lo hace (Pizarro, 
2007), que "el ejercicio de la facultad constituye una expresión de la fuerza obligatoria del contrato" (p. 413). De no encontrarse un vicio en la expresión del consentimiento, dicha cláusula debe considerarse justa por la sola existencia de la misma dentro del contrato, por cuanto se deriva del previo acuerdo de la voluntad de todas las partes, así los efectos de la aplicación de la misma, solo opere para una de ellas.

A manera de opinión, el que la prerrogativa sea pactada a favor de solo una de las partes, no debería ser considerada una práctica abusiva, si se tiene en cuenta que, en todos los casos, la misma deberá encontrarse cumpliendo o allanarse de cumplir con las obligaciones del contrato que a su vez le correspondan, para que la misma sea ejercida lícitamente, regla de operación revisada, establecida claramente a favor del deudor.

Adicionalmente, siempre será posible para el juez, en el ejercicio interpretativo que haga sobre la licitud de la cláusula, el verificar la buena fe del acreedor entendida en forma activa; o mejor, revisar si existió por parte de este, un despliegue de actuaciones que evidencien el haber cooperado con el deudor en el cumplimiento de las obligaciones que este tenga a su cargo (Navia, 2008).

Siguiendo con el análisis de las reglas para la operación de la terminación unilateral convencional que comúnmente se pactan en la práctica contractual, respecto del carácter de grave o esencial que debe ostentar el incumplimiento por el cual se produce la terminación unilateral del contrato, se observa que son las partes quienes determinan las obligaciones cuyo incumplimiento es suficiente para producir la terminación del mismo, siguiendo de esta manera la tesis ya revisada de Molina (2009).

En este sentido, no habría duda en concluir que todos los incumplimientos susceptibles de resolución de acuerdo al criterio de las partes, pueden ser considerados incumplimientos esenciales y todos aquellos que se consideren graves o trascendentes por las partes, son esenciales (Polo, 2019).

En el laudo del Tribunal Arbitral de Marco Aldany Colombia SAS en contra de la sociedad Sueños y Franquicias Emaús SAS (Cámara 
de Comercio de Bogotá. CAC, 2017c), mediante la cual se solicita se ratifique la terminación del contrato de franquicia celebrado entre estos, por haber incumplido el franquiciado Sueños y Franquicias Emaús, una o algunas de las obligaciones contractuales. Se observó que la facultad se pactó a favor de Marco Aldany Colombia, quien podría terminar el contrato, cuando el franquiciado incurriera en el incumplimiento de cualquiera de las cláusulas y causales de incumplimiento señaladas en el contrato, sin hacer distinción respecto de si se trata de obligaciones esenciales o no.

Dentro de las excepciones de méritos formuladas por el franquiciado, el mismo alegó en varias oportunidades, mala fe en el franquiciante por el hecho de haber redactado el contrato. A pesar de que el franquiciado no presentó los argumentos y las pruebas necesarias que sustentaran su excepción, fácilmente se puede concluir que lo que se pretendió fue establecer que no existió un acuerdo en la formación del contenido del contrato, dentro del cual se encuentra la cláusula de terminación unilateral. Como era de esperarse, el Tribunal Arbitral la descartó argumentando que las partes tienen la obligación "de proveer al juez los elementos probatorios suficientes para verificar los hechos del caso" (Cámara de Comercio de Bogotá-CCB, CAC, 2017c).

Abordar un cuestionamiento acerca de si dichas cláusulas o causales de incumplimiento incluidas como causa para la operación de la terminación unilateral, ostentan la calidad de esenciales y que las mismas sean o no susceptibles de producir la terminación del contrato, debería ser labor del Juez, de manera eventual, cuando el deudor decida ponerlo bajo su conocimiento; pues, se considera que el privar a las partes del privilegio de organizar sus asuntos, dentro del ejercicio de su autonomía, en nada contribuye con el concepto revisado sobre la propensión de la contratación moderna, de proveer soluciones ágiles de los conflictos entre particulares.

No obstante, en estos casos, una manera que podría tener el juez de determinar la gravedad del incumplimiento de las obligaciones que enuncien explícitamente los contratantes, consiste en verificar si éstos otorgaron un plazo para que la parte incumplida 
subsane el incumplimiento; de no otorgarse un plazo, podría considerarse que el incumplimiento es tan grave que no da a lugar a que el mismo se siga ejecutando, por lo que, contrario a la regla expuesta previamente, en este caso, se podría creer que las partes consideraron que el ejercicio de la terminación unilateral debería operar automáticamente. En el laudo mencionado, por ejemplo, las partes no establecieron un plazo para que el deudor corrigiera su conducta.

A manera de opinión, se considera que el hecho de no haber establecido un plazo, abre un camino para que se ejerza el derecho de opción que tiene el acreedor, este es, la parte cumplida que ostenta el derecho, de escoger entre el cumplimiento o, ante el fracaso de este, desistir del mismo y pretender la resolución del contrato; derecho de elección que las partes consintieron que quedara pactado en una cláusula (Hinestrosa, 2016). No hay que olvidar que el incumplimiento constituye un factor que altera el régimen normativo establecido en el contrato, y en consecuencia lo que conviene es garantizar la protección del interés del acreedor (Ibañez, 2003). Sin embargo, siempre será una opción, el que la parte con la prerrogativa decida no terminar el contrato y encontrar una manera de lograr el cumplimiento del mismo, de acuerdo al Código Civil (1873, art. 1546) y al Código de Comercio (1971, art. 870).

Por el contrario, si el caso que se presenta es aquel, en que las partes no hacen claridad acerca de las obligaciones cuyo incumplimiento producen la terminación unilateral del contrato, pero las mismas otorgan un plazo para que la parte incumplida subsane su falta, lo que se podría inferir es que la facultad de terminación unilateral, es susceptible de operar cuando el incumplimiento recaiga sobre obligaciones principales o accesorias, indiscriminadamente.

En estos casos, de una parte, es evidente que el plazo que se otorgue para subsanar el incumplimiento, constituye el límite o el control impuesto en la cláusula, para que la parte con la prerrogativa no abuse de su potestad; o lo que en la doctrina se le identifica, como se vio, como una carga de la autonomía privada de los contratantes, 
que les permite a los mismos disfrutar de la libertad que poseen para autorregular sus intereses, sin caer en abuso (Bernal-Fandiño, 2016, p. 65).

De otra parte, con el otorgamiento de un plazo para que el contratante incumplidor cumpla el contrato, con la advertencia de que, de no hacerlo, el mismo queda resuelto, se evitaría que un incumplimiento no esencial, pero continuado, mantenga indefinidamente vinculado al otro contratante (Morales, 2016). Un mecanismo de control adicional, con base en los requisitos estudiados previamente, en los casos en que las partes no señalen taxativamente las obligaciones cuyo incumplimiento producen la terminación; podría consistir en que, en esos casos, la facultad de terminar el contrato unilateralmente, se pacte para todas las partes y no solo a favor de una de ellas.

\section{Resultados}

Algunos de los ejemplos presentados fueron tomados de los hallazgos producto de la revisión de las cláusulas de terminación unilateral analizadas en los laudos arbitrales escogidos conforme a la metodología enunciada previamente; haciendo un análisis de las mismas con base en los grupos de requisitos de operación estudiados (Tabla 1):

TABLA 1.

Revisión laudos arbitrales

Laudo

* Tipo de contrato
Tipo de terminación unilateral pactada y reglas de uso evidenciadas
BAVARIA S.A. podrá dar por terminado con justa causa el contrato que surja en caso de que esta oferta sea aceptada, en cualquiera de la siguientes situaciones:

(...) f.- Cuando unilateralmente BAVARIA S.A. decida dar por terminado el contrato que surja en caso de la aceptación de esta oferta siempre que me comunique su decisión por escrito y con una anticipación no menor de treinta (30) días.
Terminación unilateral ad nutum.

Titularidad del derecho: Se pactó a favor de solo una de las partes (BAVARIA S.A.) Requisito de operación: Preaviso de treinta (30) días. de Distribución 


\begin{tabular}{ccc}
\hline Laudo & Tipo de terminación \\
* Tipo de contrato & Texto de la cláusula & $\begin{array}{c}\text { unilateral pactada y reglas } \\
\text { de uso evidenciadas }\end{array}$ \\
\hline
\end{tabular}

Tribunal Arbitral
de Automotora
Nacional S.A.
- Autonal S.A.
Contra Sociedad
de

Fabricación de Automotores S.A. Sofasa S.A. (BBC, 2017b)
${ }^{*}$ Contrato atípico de Concesión

Tribunal Arbitral de Fundación Oftalmológica Nacional Contra Iris Soluciones S.A. (CCB, 2017d)

*Arrendamiento de una Plataforma de Software y "Consultoría Especializada"

Tribunal Arbitral de Marco Aldany Colombia S.a.s. Contra Sueños y Franquicias Emaús S.A.S. (CCB, 2017c)

${ }^{*}$ Contrato de Franquicia
Cualquier parte podrá dar por terminado el presente contrato en cualquier momento a través del aviso escrito dirigido a la otra parte con seis (6) meses de antelación a la fecha de que se busque su terminación, término que las partes han considerado suficiente y acorde con la naturaleza de las operaciones objeto de la concesión. (...) Para dar por terminado el contrato al amparo de lo que se prevé en este aparte, no se precisará que exista, señalar ninguna causal y se entenderá que por motivo de la terminación no se causa ningún perjuicio y no habrá lugar a ninguna indemnización. (...)

El presente contrato lleva implícita la condición resolutoria, de tal suerte que se podrá dar por terminado por cualquiera de las partes ante el incumplimiento de ellas". "En el evento que los incumplimientos se den por alguna de las partes, la parte afectada por el incumplimiento comunicará a la otra del mismo por escrito para que subsane el incumplimiento. Si no se subsana dentro de los sesenta (60) días calendario la parte afectada queda facultada para dar por terminado unilateralmente el presente contrato".

El Franquiciante podrá rescindir* el presente contrato cuando el franquiciado incurra en el incumplimiento de cualquiera de las cláusulas y causales de incumplimiento señaladas en este contrato. ... la rescisión operará de pleno derecho, sin necesidad de resolución judicial..." "Luego de un trabajo interpretativo del Tribunal, se concluye lo siguiente acerca de esta expresión utilizada en el texto del contrato: "entiende el Tribunal que la expresión rescisión es usada en el contrato como equivalente una cláusula de terminación o condición resolutoria expresa”.
Terminación unilateral ad nutum.

Titularidad del derecho: Se pactó a favor de ambas partes.

Requisito de operación:

Preaviso de seis (6) meses.

Terminación unilateral por Incumplimiento.

Titularidad del derecho: Se pactó a favor de ambas partes.

Requisito de operación: Plazo de sesenta (60) días para subsanar el incumplimiento.

Terminación unilateral por Incumplimiento.

Titularidad del derecho: A favor de solo una de las partes (El franquiciante)

Se enuncia cuáles son las obligaciones cuyo incumplimiento generan la terminación del contrato. 


\begin{tabular}{|c|c|c|}
\hline $\begin{array}{c}\text { Laudo } \\
\text { * Tipo de contrato }\end{array}$ & Texto de la cláusula & $\begin{array}{c}\text { Tipo de terminación } \\
\text { unilateral pactada y reglas } \\
\text { de uso evidenciadas }\end{array}$ \\
\hline $\begin{array}{l}\text { Tribunal Arbitral } \\
\text { de Tecnología } \\
\text { y Desarrollo de } \\
\text { Colombia S.A.S. } \\
\text { Contra Banco de } \\
\text { Comercio Exterior } \\
\text { de Colombia S.A. } \\
\text { (BBC, 2017a) } \\
\text { * Contrato de } \\
\text { Prestación de } \\
\text { Servicios }\end{array}$ & $\begin{array}{l}\text { CLÁUSULA DÉCIMA QUINTA. } \\
\text { TERMINACION DEL CONTRATO: El } \\
\text { presente contrato terminará por cualquiera de } \\
\text { las siguientes causas: (...) 2. EL BANCO podrá } \\
\text { dar por terminado el Contrato unilateralmente } \\
\text { en caso de incumplimiento de las obligaciones } \\
\text { radicadas en cabeza de EL CONTRATISTA } \\
\text { que impida la ejecución del objeto contractual, } \\
\text { en cuyo caso se configuraría una justa causa } \\
\text { para dar por terminado el contrato sin lugar al } \\
\text { pago de indemnización alguna a favor de EL } \\
\text { CONTRATISTA. Para el efecto, EL BANCO } \\
\text { avisará de la situación de incumplimiento } \\
\text { mediante comunicación escrita dirigida a } \\
\text { EL CONTRATISTA, el cual contará con un } \\
\text { plazo de treinta (30) días calendario contado a } \\
\text { partir de la fecha de envío de la comunicación } \\
\text { para corregir el incumplimiento de la parte. } \\
\text { Si no se ha corregido el incumplimiento dentro } \\
\text { del plazo mencionado, EL BANCO queda en } \\
\text { libertad de dar por terminado el contrato. } \\
\text { (...) 4. Por decisión unilateral de EL BANCO } \\
\text { y sin justa causa en cualquier momento. } \\
\text { Dicha terminación se notificará a EL } \\
\text { CONTRATISTA en la dirección de notificación } \\
\text { judicial, con noventa (90) días calendario de } \\
\text { anticipación a la fecha en que se espera surta } \\
\text { efecto la terminación (...) }\end{array}$ & $\begin{array}{l}\text { Terminación unilateral por } \\
\text { Incumplimiento } \\
\text { Titularidad del derecho: } \\
\text { A favor de solo una de las } \\
\text { partes (BANCOLDEX) } \\
\text { El incumplimiento debe ser } \\
\text { aquel que "impida la ejecución } \\
\text { del objeto contractual" } \\
\text { Requisito de operación: Plazo } \\
\text { de treinta (30) días calendario } \\
\text { para que la parte incumplida } \\
\text { corrija el incumplimiento. } \\
\text { Terminación unilateral ad } \\
\text { nutum } \\
\text { Titularidad del derecho: } \\
\text { A favor de solo una de las } \\
\text { partes (BANCOLDEX). } \\
\text { Requisito de operación: } \\
\text { Preaviso de } 90 \text { días } \\
\text { calendario. }\end{array}$ \\
\hline $\begin{array}{l}\text { Tribunal Arbitral } \\
\text { de Pert D.P.M. } \\
\text { S.A. Contra } \\
\text { Wood Group Psn } \\
\text { Colombia S.A. } \\
\text { (CCB, 2013) }\end{array}$ & $\begin{array}{l}\text { 10. TERMINACIÓN DEL CONTRATO } \\
\text { El presente Contrato se entenderá terminado } \\
\text { por (...) b) El incumplimiento de las obligaciones } \\
\text { contractuales a cargo de EL CONTRATISTA, } \\
\text { caso en el cual se terminará anticipadamente } \\
\text { por WOOD GROUP PSN y habrá lugar a } \\
\text { indemnización de perjuicios a favor de WOOD } \\
\text { GROUPPSN por parte de EL CONTRATISTA. }\end{array}$ & $\begin{array}{l}\text { Terminación unilateral por } \\
\text { Incumplimiento. } \\
\text { Titularidad del derecho: } \\
\text { A favor de solo una de las } \\
\text { partes (WOOD GROUP } \\
\text { PSN). } \\
\text { Terminación unilateral ad } \\
\text { nutum. }\end{array}$ \\
\hline $\begin{array}{l}\text { * Contrato de } \\
\text { Servicios de } \\
\text { Montaje Electro- } \\
\text { mecánico }\end{array}$ & $\begin{array}{l}\text { c) Unilateralmente por parte de WOOD } \\
\text { GROUP PSN, previa comunicación por escrito } \\
\text { a EL CONTRATISTA con no menos quince } \\
\text { (15) días de anticipación. Caso en el cual no } \\
\text { habrá lugar a indemnización a favor de EL } \\
\text { CONTRATISTA. (...) }\end{array}$ & $\begin{array}{l}\text { Titularidad del derecho: } \\
\text { A favor de solo una de las } \\
\text { partes (WOOD GROUP } \\
\text { PSN). } \\
\text { Requisito de operación: } \\
\text { Preaviso de quinde (15) días. }\end{array}$ \\
\hline
\end{tabular}

Fuente: Autores a partir de BBC (2017a; 2017b; 2017c; 2017d; 2013; 2011). 


\section{ConClusiones}

\section{Conclusiones relacionadas con la terminación unilateral convencional}

A partir de los requisitos de operación de la cláusula de terminación unilateral revisadas en la doctrina, en conjunto con las cláusulas analizadas en los laudos arbitrales estudiados, es posible señalar en primer lugar, que los particulares en Colombia, al momento de disponer de sus intereses, pactan cláusulas de terminación unilateral en sus contratos a pesar de que no existe normativa que se encargue de regular su ejercicio, pues los mismos tienden a acudir a aquellas reglas propias de tipos contractuales existentes.

Sin embargo, la labor creativa de los contratantes en ejercicio de la autonomía privada, conforma el elemento principal en la redacción de estas cláusulas, y bajo este entendido, será labor del juez, en el evento en el que llegare a ser de su conocimiento, el catalogar las mismas como abusivas, conforme a los deberes inherentes a los principios de buena fe y a la cláusula general de abuso del derecho.

\section{Conclusiones generales acerca de la cláusula de terminación unilateral}

En ejercicio de las potestades establecidas en el Código Civil (1873, art. 1602), las partes, en el momento de la negociación, tratativas o celebración del contrato, tienen la facultad de establecer dentro del contenido del mismo, las formas de terminación que operarán en su ejecución, dentro de las cuales se encuentra la terminación unilateral; y por esta razón gozarán de presunción legal siempre que dicho contrato exista y sea válido. Adicionalmente, lo anterior es posible, dado que no existe norma que prohíba el pacto de una forma de terminación unilateral y la ley colombiana la reconoce para unos específicos tipos contractuales.

El pacto de la terminación unilateral convencional solo podría tener lugar para los tipos contractuales que no tienen respaldo de una norma específica, así como para los contratos atípicos y no podrá ser admisible en los contratos de adhesión dado que la misma debe ser el resultado 
de una discusión y negociación previa de las partes y de la aceptación de los términos por las mismas.

Conclusiones acerca de las reglas de operación de la cláusula de terminación unilateral

Se proponen las siguientes reglas generales de operación bajo el entendido de que no es posible establecer en una sola lista, todos los requisitos para la operación de las cláusulas que contengan la facultad excepcional de terminar unilateralmente un contrato, por cuanto las mismas deben ser interpretadas teniendo en cuenta cada caso particular.

1. Respecto a la terminación unilateral convencional por incumplimiento, dado que el proceso de escoger cuál o cuáles son las obligaciones cuyo incumplimiento ostenta el carácter de grave o esencial, depende de lo que estas características representen para las partes en su discrecionalidad; los particulares deberán indicar claramente dentro de la cláusula, la obligación u obligaciones cuya inobservancia, relevante, total o parcial, facultará a una o a todas las partes a operar la terminación unilateral del contrato. Con esto, se minimizaría el riesgo de que perdure en el tiempo la ejecución de un contrato que ha sido incumplido, pero que, por no considerarse un incumplimiento grave o esencial, se mantenga vivo de manera indefinida.

2. La prerrogativa de terminar unilateralmente un contrato podrá ser pactada para todas las partes o solo para una de estas. Sin embargo, se considera pertinente para los casos en que las partes no señalen de forma expresa las obligaciones cuyo incumplimiento producen la terminación, la cláusula deberá ser pactada para todas las partes.

3. En todos los casos, ya sea que opere la terminación unilateral ad nutum o por incumplimiento, la parte con la prerrogativa deberá informar a la otra. En caso de incumplimiento, el acreedor deberá constituir en mora al deudor, a través de una comunicación que puede ir acompañada de un plazo para que este tenga la oportunidad de corregir su conducta; o también puede tratarse solo de un preaviso, a través del cual solo se informa acerca de la terminación automática del contrato. 
Particularidades acerca de los límites al acreedor en el ejercicio de la cláusula de terminación unilateral

La legitimidad del acreedor de operar la terminación unilateral convencional dependerá de la irreprochabilidad de su conducta, por cuanto el mismo deberá encontrarse cumpliendo con las obligaciones derivadas del contrato o por lo menos, allanarse de cumplirlas.

Para el caso en que la terminación sea pactada para solo una de las partes, el acreedor siempre deberá actuar de buena fe, entendida en forma activa; en la medida en que este deberá desplegar las actuaciones que evidencien el haber cooperado con el deudor, en el cumplimiento de las obligaciones que este tenía a su cargo.

\section{REFERENCIAS}

Arroyo, J. F. (2008). La terminación unilateral del contrato de derecho privado. Revista de Derecho Privado, (14), 35-51. Disponible en https://revistas.uexternado.edu.co/index. php/derpri/article/view/549

Bernal-Fandiño, M. (2016). El principio de la solidaridad como límite a la autonomía privada. Revista Jurídicas, 13(2), 60-70. Disponible en http://190.15.17.25/juridicas/index. php?option $=$ com_content\&view $=$ article\&id $=130$

Bernal-Fandiño, M. (2013). Deber de coherencia en el derecho colombiano de los contratos. Bogotá D.C.: Editorial Pontificia Universidad Javeriana.

Bernal-Fandiño, M. (2007). El solidarismo contractual-Especial referencia al derecho francés. Universitas, 56(144), 15-30. Disponible en https://revistas.javeriana.edu.co/index.php/ vnijuri/article/view/14588

Betancur, G., Londoño, C. y Múnera, M. (2017). Las cláusulas excepcionales en la contratación estatal. Nuevo Derecho, 13(21), 111-145. Obtenido de http://revistas.iue.edu.co/index.php/nuevoderecho/article/download/1012/1288 
Botero, L. (2007). Apuntes sobre la terminación unilateral de los contratos en el derecho privado colombiano. En, J. Gaitán y F. Mantilla (Coord.), La terminación del contrato: nuevas tendencias del Derecho comparado (pp. 365-390). Bogotá, D.C.: Universidad del Rosario. Disponible en http:// repository.urosario.edu.co/handle/10336/1009

Cámara de Comercio de Bogotá. Centro de Arbitraje y Conciliación. (9 de abril de 2017a). Laudo (Tribunal arbitral de Tecnología y desarrollo de Colombia SAS contra Banco de Comercio Exterior de Colombia S.A.). [Radicado 4037]. Disponible en https://bibliotecadigital.ccb.org.co/handle/11520/21307

Cámara de Comercio de Bogotá. Centro de Arbitraje y Conciliación. (25 de abril de 2017b). Laudo (Tribunal arbitral de Automotora Nacional S.A. - AUTONAL S.A. Contra Sociedad de Fabricación de Automotores S.A. -SOFASA S.A.). [Radicado 4011]. Disponible en https://bibliotecadigital.ccb. org.co/handle/11520/21312

Cámara de Comercio de Bogotá. CAC. (8 de septiembre de 2017c). Laudo (Tribunal de Arbitramento de Marco Aldany Colombia S.A.S. contra Sueños y Franquicias Emaús S.A.S.). [Radicado 4562]. Disponible en https://bibliotecadigital. ccb.org.co/handle/11520/21370

Cámara de Comercio de Bogotá. Centro de Arbitraje y Conciliación. (23 de octubre de 2017d). Laudo (Tribunal Arbitral Fundación Oftalmológica Nacional FON contra Iris Soluciones S.A.). [Radicado 4368]. Disponible en https://bibliotecadigital.ccb.org.co/handle/11520/21380

Cámara de Comercio de Bogotá. Centro de Arbitraje y Conciliación. (27 de agosto de 2013). Laudo Arbitral (Tribunal de arbitramento de PERT D.P.M. S.A. contra Wood Group PSN Colombia S.A.). [Radicado 2430]. Disponible en http://hdl. handle.net/11520/22196 
Cámara de Comercio de Bogotá. CAC. (29 de agosto de 2011). Laudo Arbitral (Tribunal Arbitral Proveza Ltda contra Bavaria S.A.). [Radicado 1901]. Disponible en http://hdl.handle.net/11520/22032

Gual, J. M. (2016). Las cláusulas abusivas - Evolución hacia una noción. Revista Verba Iuris, (36), 113-134. https://doi. org/10.18041/0121-3474/verbaiuris.36.1017

Hinestrosa, F. (2016). Tutela del acreedor frente al deudor incumplido. Revista de Derecho Privado, (31), 5-21. http://dx.doi. org/10.18601/01234366.n31.01

Hinestrosa, F. (2014). Función, límites y cargas de la autonomía privada. Revista de Derecho Privado, (26), 5-39. Disponible en https://revistas.uexternado.edu.co/index.php/derpri/ article/view/3794

Hinestrosa, F. (2013). Autonomía privada y tipicidad contractual. Revista de Derecho Privado, (24), 3-13. Disponible en https://revistas.uexternado.edu.co/index.php/derpri/article/view/3300

Hinestrosa, F. (2007). Terminación unilateral del contrato. En, A. Kemelmajer, Responsabilidad Civil (pp. 429-461). Buenos Aires: Rubinzal-Culzoni.

Ibañez, C. M. (2003). Resolución por incumplimiento. Buenos Aires: Astrea de Alfredo y Ricardo Depalma.

Maldonado, M. I. y Montaña, L. A. (2017). Arbitraje: Mecanismo alternativo de solución de conflictos o privatización judicial. Jurídicas CUC, 13(1), 121-146. http://dx.doi.org/10.17981/ juridcuc.13.1.2017.06

Mantilla, F. y Ternera, F. (2005). La resolución de los contratos en el derecho colombiano. Revista chilena de derecho privado, (5), 43-71. Disponible en http://www.rchdp.cl/index. $\mathrm{php} / \mathrm{rchdp} / \mathrm{issue} / \mathrm{archive}$ issuesPage $=2 \#$ issues

Molina, R. (2009). La terminación unilateral del contrato por incumplimiento. Revista de Derecho Privado, (17), 77-105. Disponible en https://revistas.uexternado.edu.co/index. php/derpri/article/view/411 
Molina, R. (2006). La terminación unilateral del contrato ad nutum. Revista de Derecho, 126-158. Disponible en https://revistas.uexternado.edu.co/index.php/derpri/article/view/586

Morales, A.-M. (2016). Claves de la modernización del derecho de contratos. Bogotá, D.C.: Grupo Editorial Ibañez.

Navia, F. (2008). La terminación unilateral del contrato de derecho privado. Revista de Derecho Privado, (14), 35-67. Disponible en https://revistas.uexternado.edu.co/index.php/derpri/ article/view/549

Neme, M. L. (2018). Facultades contractuales de ejercicio unilateral: cómo usarlas sin incurrir en abuso. La buena fe otorga criterios para el legítimo ejercicio del ius variandi. [Ensayos de derecho privado $N^{\circ}$ 7]. Bogotá, D.C.: Departamento de Publicaciones de la Universidad Externado de Colombia.

Neme, M. L. (2014). Pacta sunt servanda y rebus sic stantibus. Tensiones entre los principios de buena fe y autonomía contractual. En, C. Soriano, Pacta Sunt Servanda y Rebus Sic Stantibus. Desarrollos Actuales y Perspectivas Históricas. Madrid: Novum.

Oviedo-Albán, J. (2019). La cláusula de terminación unilateral del contrato. Vniversitas, 63(138). https://doi.org/10.11144/javeriana.vj138.ctuc

Pizarro, C. (2007). La ruptura unilateral del contrato. En, J. A. Gaitán y F. Mantilla, La terminación del contrato. Nuevas tendencias del derecho comparado (pp. 408-426). Bogotá, D.C.: Universidad del Rosario. Disponible en http://repository.urosario.edu.co/handle/10336/1009

Polo, C. A. (2019). Incumplimiento esencia del contrato en la legislación civil y comercial colombianas a partir del moderno derecho de contratos. Revista Vis Iuris, 6(11), 9-68. Recuperado de https://revistas.usergioarboleda.edu.co/index. php/visiuris/article/download/1270/1006/

Rengifo, E. (2014a). La terminación y la resolución unilateral del contrato. En, E. Rengifo, Las facultades unilaterales en la contratación moderna (pp. 91-135). Bogotá, D.C.: Legis. 
Rengifo, E. (2014b). El abuso del derecho como fuente autónoma de obligaciones y medio de control al contenido contractual. En, E. Rengifo, Las facultades unilaterales en la contratación moderna (pp. 137-165). Bogotá, D.C.: Legis.

República de Colombia. Congreso de Colombia. (10 de julio de 2003). Por la cual se expide el régimen de arrendamiento de vivienda urbana y se dictan otras disposiciones. [Ley 820]. Diario Oficial: 45.244. Disponible en http://www.secretariasenado.gov.co/senado/basedoc/ley_0820_2003.html

República de Colombia. Congreso de Colombia. (11 de julio de 1994). Por la cual se establece el régimen de los servicios públicos domiciliarios y se dictan otras disposiciones. [Ley 142]. Diario Oficial: 41.433. Disponible en http://www.secretariasenado.gov.co/senado/basedoc/ley_0142_1994_pr003.html

República de Colombia. Congreso de la República. (31 de mayo de 1873). Código Civil. Diario Oficial No. 2.867. Disponible en http://www.secretariasenado.gov.co/senado/basedoc/codigo_civil.html

República de Colombia. Corte Suprema de Justicia. Sala de Casación Civil y Agraria. (17 de agosto de 2016). Reg. 11001-31-03007-2007-00606-01. [Sentencia SC11287-2016]. Magistrado Ponente: Ariel Salazar Ramírez. Disponible en https:// corte-suprema-justicia.vlex.com.co/vid/679349089

República de Colombia. Corte Suprema de Justicia. Sala de Casación Civil. (23 de marzo de 2012). Reg. 11001-31-03042-2007-00067-01. [Sentencia SC2007-00067]. Magistrado Ponente: Ruth Marina Díaz Rueda. Recuperado de https://www.ramajudicial.gov.co/documents/10614/432378/ $\mathrm{C} \mathrm{ORTE}+\mathrm{S} \mathrm{U}$ PR E M A + E N E R O + - M A Y O ( 6 ) . pdf/56c989d3-7e3c-4ed2-81c1-f2d62dca010c

República de Colombia. Corte Suprema de Justicia. Sala de Casación Civil. (30 de agosto de 2011). Ref. 11001-3103-012-1999. 01957-01. Magistrado Ponente: Willian Namén Vargas. Disponible en https://corte-suprema-justicia.vlex.com.co/ vid/-316765778 
República de Colombia. Presidente de la República. (16 de junio de 1971). Código de Comercio. Diario Oficial No. 33.339. Disponible en http://www.secretariasenado.gov.co/senado/basedoc/codigo_comercio.html

Sanabria, A. (2007). La resolución en el derecho colombiano. En, J. A. Gaitán y F. Mantilla, La terminación del contrato. Nuevas tendencias de dereho comparado (pp. 139-171). Bogotá, D.C.: Universidad del Rosario. Recuperado de https://repository.urosario.edu.co/bitstream/ handle/10336/1009/La\%20Terminacion\%20del\%20contrato.pdf?sequence $=1 \&$ isAllowed $=\mathrm{y}$

*Artículo inédito de reflexión. Desarrollado como requisito de grado para la obtención del título de Magister en Derecho con Énfasis en Derecho Privado del Colegio Mayor de Nuestra Señora del Rosario.

Katherine Marrugo Saldarriaga es Especialista en Derecho Contractual y Relaciones Jurídico Negociales de la Universidad Externado de Colombia. Abogada de la Universidad del Norte (Barranquilla, Colombia) y estudiante de Maestría del Colegio Mayor de Nuestra Señora del Rosario (Bogotá, Colombia). https://orcid. org/0000-0003-2233-2009 